\title{
Correction to: A shining star of congenital heart surgery-a tribute to Dr. William I Norwood Jr (1941-2020)
}

\section{Smruti Ranjan Mohanty ${ }^{1}$ (1)}

Published online: 15 June 2021

(C) Indian Association of Cardiovascular-Thoracic Surgeons 2021

Correction to: Indian Journal of Thoracic and Cardiovascular Surgery (May-June 2021) 37(3):374-375 https://doi.org/10.1007/s12055-021-01161-w

An obituary for Dr. Norwood with the title "A shining star of congenital heart surgery-a tribute to Dr. William I Norwood Jr (1941-2020)' was published in this journal in the May-June 2021 issue , 37(3), 374-375. In this publication an incorrect picture of Dr William I Norwood, was published. I, Smruti Ranjan Mohanty, as the author of this obituary, apologise for this gross error and I am providing with the correct photograph of Dr. William I. Norwood.

The online version of the original article can be found at https:// doi.org/10.1007/s12055-021-01161-w

Smruti Ranjan Mohanty

smrutiranjanmohanty699@gmail.com

1 Children's Heart Center, Kokilaben Dhirubhai Ambani Hospital, Four Bunglows, Andheri (West), Mumbai 400053, India

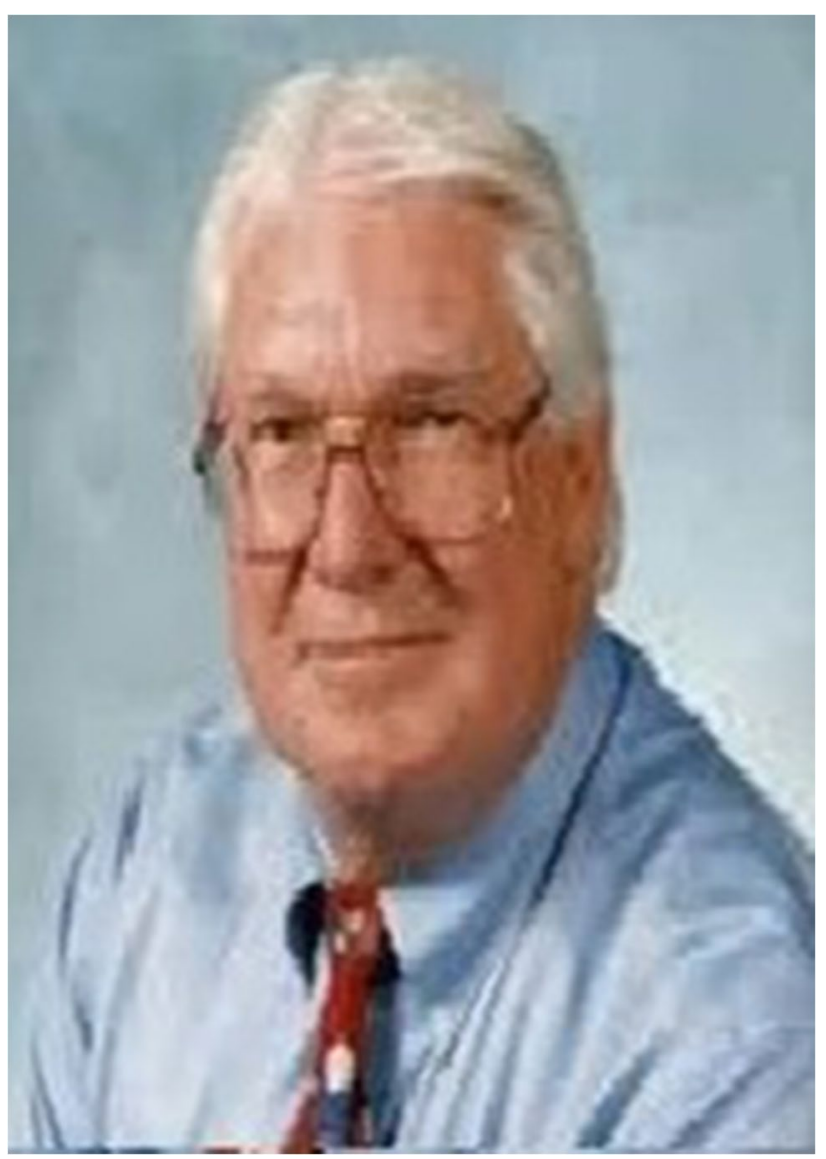

Publisher's note Springer Nature remains neutral with regard to jurisdictional claims in published maps and institutional affiliations. 